\title{
Finite Element Modeling of Cross-Ply Laminate Under Cylindrical Bending Using Plane Strain Approach
}

\author{
K V S Praveen ${ }^{1}$, B Panduranga Rao ${ }^{1}, K_{\text {Mohan }}$ Rao $^{2}$ \\ ${ }^{l}$ Civil Engineering Department, ${ }^{2}$ Mechanical Engineering Department, V. R. Siddhartha Engineering College, \\ Vijayawada520007,Andhra Pradesh, India
}

\begin{abstract}
Solid Mechanics problems are classified as $1 D, 2 D$ and $3 D$ problems based on geometry of the structure, constraints, loading and material arrangement. There are two approaches to analyze the plate known as classical bending theory and elasticity theory. The present investigation uses two-dimensional plane strain elasticity approach to solve a cylindrical bending problem which can be applied to thin as well as thick structures whereas classical bending theory is limited to analysis of thin structures only.
\end{abstract}

Keywords: Laminated plates, cylindrical bending, Finite element analysis, Orthotropic, Plane strain.

\section{Introduction}

A structural composite is a material system consisting of two or more phases on a macroscopic scale, whose mechanical performance and properties are designed to be superior to those of the constituent materials acting independently. One of the phases is usually discontinuous, stiffer and stronger and is called reinforcement, where as the less stiff and weaker phase is continuous and is called matrix. Examples of composite systems include concrete reinforced with steel and epoxy reinforced with graphite fibers, etc.

[Pagano, 1969] investigated limitations of classical laminated plate theory comparing with the solutions of several specific boundary value problems to the corresponding theory of elasticity solutions. He concluded that conventional plate theory leads to a very poor description of laminate response at low span to depth ratio but converges to the exact solution as this ratio increases. Later on he [Pagano, 1970] studied the behavior of cylindrical bending of a bidirectional laminate i.e. cross-ply laminate $(0,90)$, which further extended to the behavior of a four edge pinned rectangular plate. He [Pagano, 1970] further extended his study on cylindrical bending of plates considering the influence of shear coupling. He formulated three-dimensional elasticity solution for the static bending of composite laminates in which the axes of elastic symmetry of the various layers are parallel to the plate axes. He also considered that the state of plane strain cannot exist under the general conditions of material symmetry which was already discussed by [Lehknitskii, 1963]. [Kerr, 1968] proposed Extended Kantorovich Method (EKM) for 2D elasticity problems which further extended to 3D elasticity problem for a transversely loaded angle-ply laminate in cylindrical bending. [Kerr, 1968] proposed Extended Kantorovich Method (EKM) for 2D elasticity problems which further extended to 3D elasticity problem for a transversely loaded angle-ply laminate in cylindrical bending. Very recently, using EKM [Kerr, 1968] [Santosh Kapuria and Poonam Kumari, 2011] obtained a solution of laminated composite plate in cylindrical bending. [Ji-fan He, 1992] refined shear deformation theory for cylindrical bending of arbitrary cross-ply laminated plates. He examined the accuracy of the shear deformation theory by applying it to a cylindrical bending problem of laminated plates which has been solved exactly and concluded that the shear deformation theory can predict transverse displacement and in-plane displacement and normal stress at low span- to-thickness ratios. [Ren, 1986] presented an exact solution for the problem of an infinite cantilever anisotropic plate with only a single plane of elastic symmetry and with elastic coefficients changing through the thickness. [Ashraf, 2007] established the bending problem of cross-ply laminated plates using the threedimensional elasticity equations as well as the technique based on the state space concept and provided a strong mathematical tool allowing one to determine, in an exact and unified manner, the state of stress and displacement of cross-ply laminated composites and sandwich plates.

\section{Problem Modeling}

\subsubsection{Problem Statement}

The objective of the present investigation is to solve a cross-ply laminate subjected to uniform transverse pressure of $1 \mathrm{MPa}$ and supported along two opposite edges so that the plate bends in a cylindrical manner. The length of the supporting sides is assumed infinitely long. The cross sectional dimensions are fixed so that the span to depth ratio (s) takes the values from 50 (thin plate) to 5 (thick plate) using 2D finite element method based on plane strain approach. 


\subsubsection{Three-layered orthotropic laminate}

A three layered orthotropic laminate is modeled using ANSYS software. Symmetric (90/0/90, 0/90/0) orientations are used as a stacking sequence in the plate. The element used in the analysis is solid 4 node PLANE 42 element of ANSYS software [Ansys reference manual, 2011] which is developed based on twodimensional elasticity theory and is defined by 4 nodes having two degrees of freedom at each node: translation in node $\mathrm{x}$ and $\mathrm{y}$ directions. The properties of the constituent materials used for the present analysis are given in Table 1 and Table 2. The plate is subjected to uniform transverse pressure of 1MPa. The problem is analyzed using different boundary conditions such as hinge-roller, clamp-clamp, clamp-free. The quality of the mesh is fixed in order to satisfy the known values of transverse normal and shear stresses at the top and bottom faces of the plate.

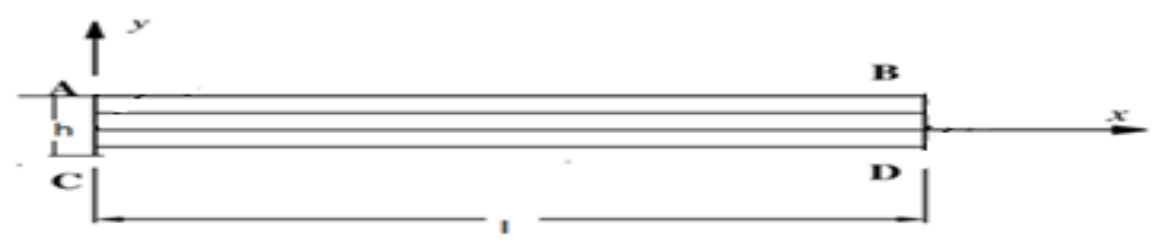

Figure 1(a) Three-layered orthotropic laminate

Table 1: Material Properties

\begin{tabular}{llll}
\hline Material & $\mathrm{E}(\mathrm{GPa})$ & $v$ & $\mathrm{G}(\mathrm{GPa})$ \\
Graphite-epoxy & $\mathrm{E}_{1}=141.6764$ & $v_{12}=0.257$ & $\mathrm{G}_{12}=4.03$ \\
& $\mathrm{E}_{2}=12.386$ & $v_{13}=0.4206$ & $\mathrm{G}_{13}=4.3592$ \\
& $\mathrm{E}_{3}=12.386$ & $v_{23}=0.257$ & $\mathrm{G}_{23}=4.03$ \\
\hline
\end{tabular}

Table 2: Material Properties

\begin{tabular}{llll}
\hline Material & $\mathrm{E}(\mathrm{GPa})$ & $\mathrm{v}$ & $\mathrm{G}(\mathrm{GPa})$ \\
Graphite-epoxy & $\mathrm{E}_{1}=172.3$ & $\mathrm{v}_{12}=0.25$ & $\mathrm{G}_{12}=1.379$ \\
& $\mathrm{E}_{2}=6.894$ & $\mathrm{v}_{13}=0.25$ & $\mathrm{G}_{13}=3.447$ \\
& $\mathrm{E}_{3}=6.894$ & $\mathrm{v}_{23}=0.25$ & $\mathrm{G}_{23}=1.379$ \\
\hline
\end{tabular}

\section{Results And Discussion}

Application of two-dimensional plane strain approach for solving an infinitely long cross-ply laminate is already discussed by [Praveen 2012, 12] my earlier paper "analysis of a cross-ply laminate under cylindrical bending using plane strain approach".

The following Figs. show the variation of deflection and bending stress with respect to different $\mathrm{S}$ values such as $5,10,20,30,40,50$ for symmetric $(0 / 90 / 0,90 / 0 / 90)$ laminates with various boundary conditions like clamped (Figs. $4 \& 5$ ), hinged (Figs. $6 \& 7$ ) and clamp-free (Figs. $8 \& 9$ ) and different materials.

From the Figs. 2 and 3 it is observed that in a simply supported boundary condition with the increase in $\mathrm{S}$ value the deflection and stresses increases in a curvilinear form and maximum values obtained in a stacking sequence of 90/0/90, minimum values obtained in a stacking sequence of 0/90/0. This is due to more stiffness of second configuration at the outer layers. 


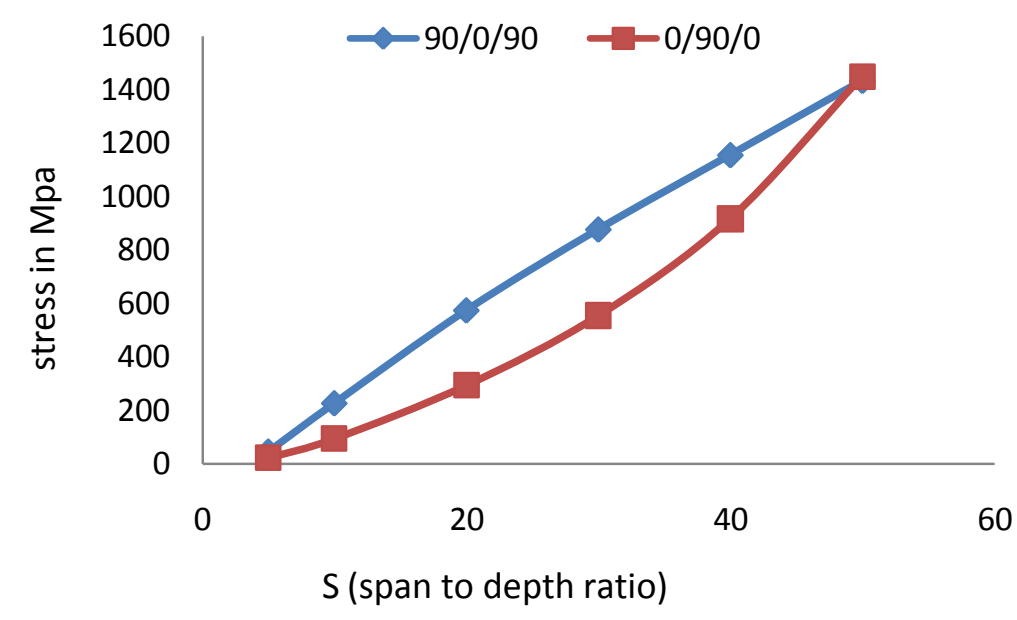

Figure 2 variation of stress with respect to $\mathrm{S}$ for hinge-roller laminate

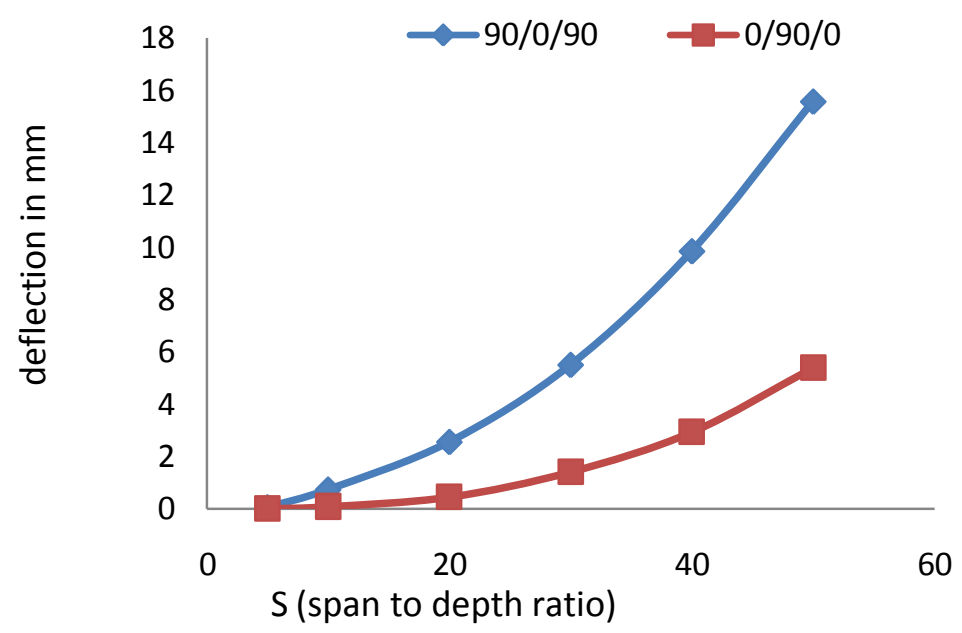

Figure 3 variation of deflection with respect to $S$ for hinge-roller laminate

From Figs. 4 and 5 it is observed that in clamp-free condition also the graphs for deflection and stresses follows the same pattern as in the case of clamped boundary condition but the values in this case are very high because one end is free which deflects more and stresses developed at the other end are also very high. Here also maximum values obtained in a stacking sequence of 90/0/90, minimum values obtained in a stacking sequence of $0 / 90 / 0$.

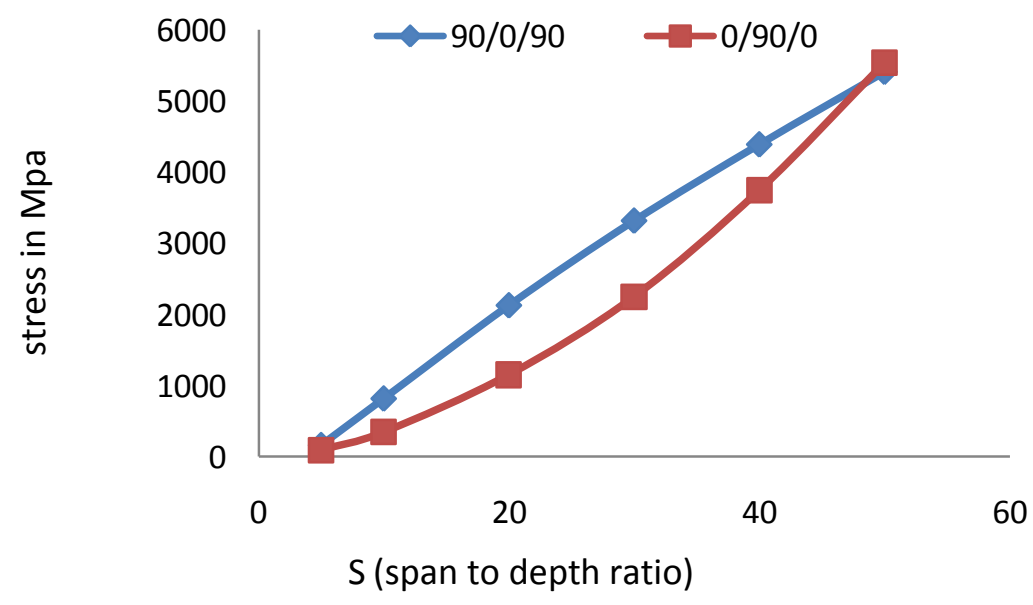

Figure 4 variation of stress with respect to $S$ for clamp-free laminate 


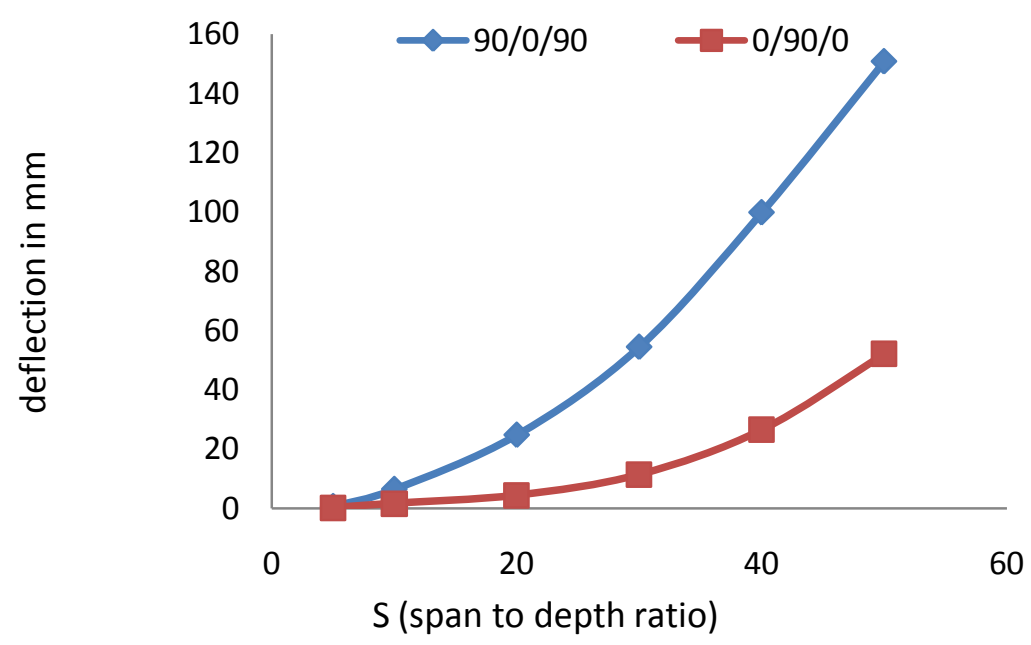

Figure 5 variation of deflection with respect to $S$ for clamp-free laminate

From Figs. 6 and 7 it is observed that in clamp-clamp condition also the graphs for deflection and stresses follows the same pattern as above two cases but the values in this case are little less than the hinged condition. Here also maximum deflection and stress values are obtained in a stacking sequence of 90/0/90 and minimum values are obtained in a stacking sequence of 0/90/0. It is observed that maximum stress is developed at supports in the stacking sequences that start with $0^{0}$. This is due to the axial compression developed and due to high stiffness of the bottom layer. In these cases also the maximum stresses developed at the center are considered in order to maintain similarity between all the cases by neglecting the end effects.

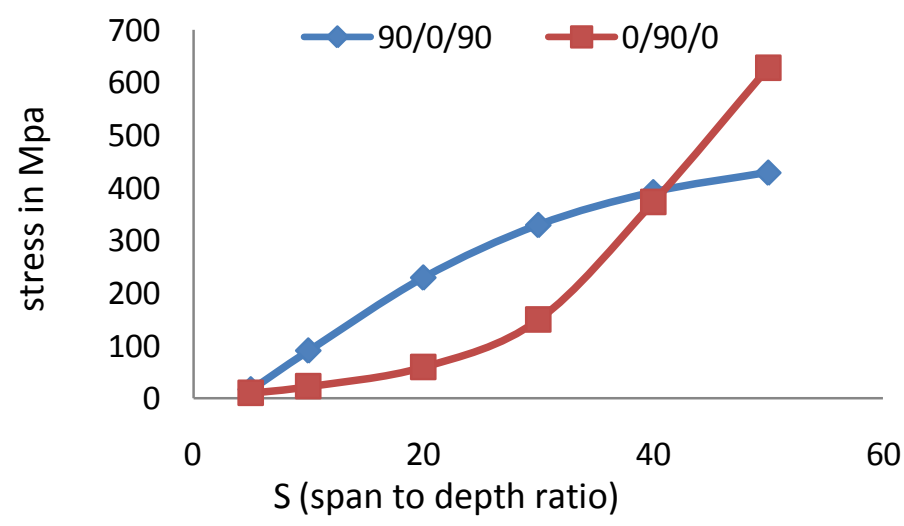

Figure 6 variation of stress with respect to $S$ for clamp-clamp laminate

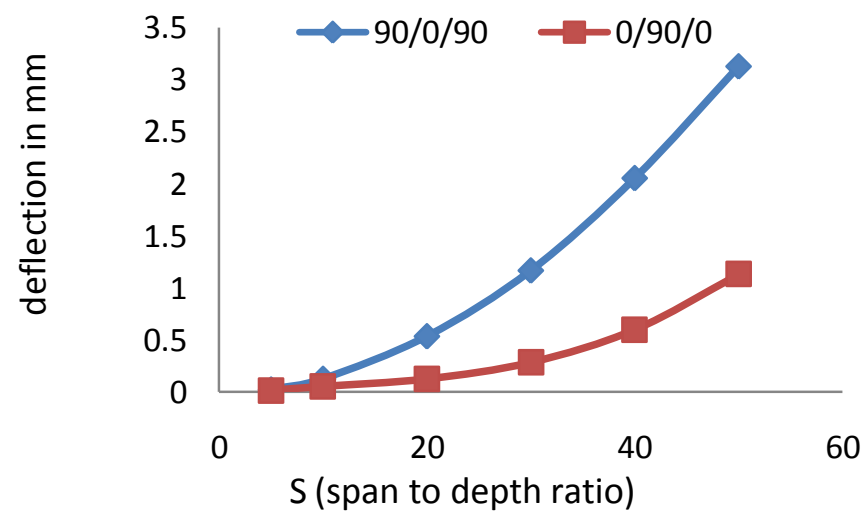

Figure 7 variation of deflection with respect to $S$ for clamp-clamp laminate 
From the Figs. 8 and 9 it is observed that in a simply supported boundary condition with the increase in $\mathrm{S}$ value the deflection and stresses increases in a curvilinear form and maximum values obtained in a stacking sequence of 90/0/90, minimum values obtained in a stacking sequence of $0 / 90 / 0$. This is due to more stiffness of second configuration at the outer layers.

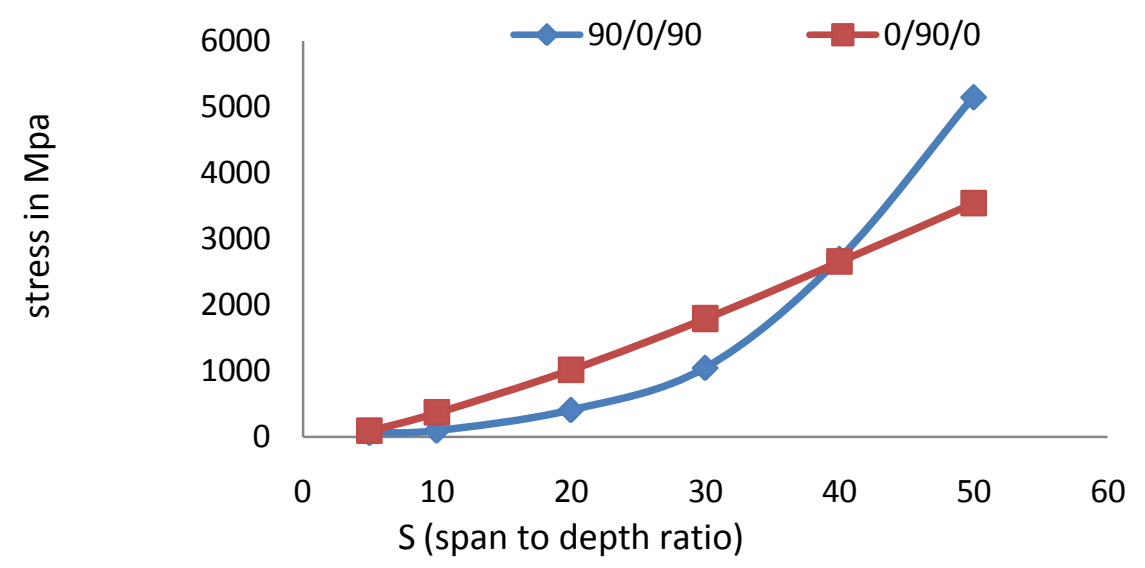

Figure 8 variation of stress with respect to $\mathrm{S}$ for hinge-roller laminate

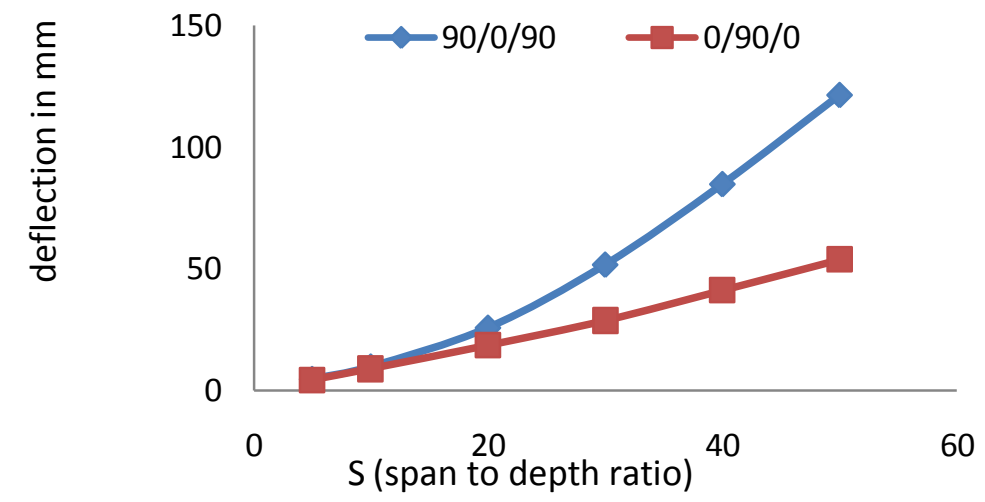

Figure 9 variation of deflection with respect to $S$ for hinge-roller laminate

From Figs. 10 and 11 it is observed that in clamp-free condition also the graphs for deflection and stresses follows the same pattern as in the case of clamped boundary condition but the values in this case are very high because one end is free which deflects more and stresses developed at the other end are also very high. Here also maximum values obtained in a stacking sequence of 90/0/90, minimum values obtained in a stacking sequence of $0 / 90 / 0$.

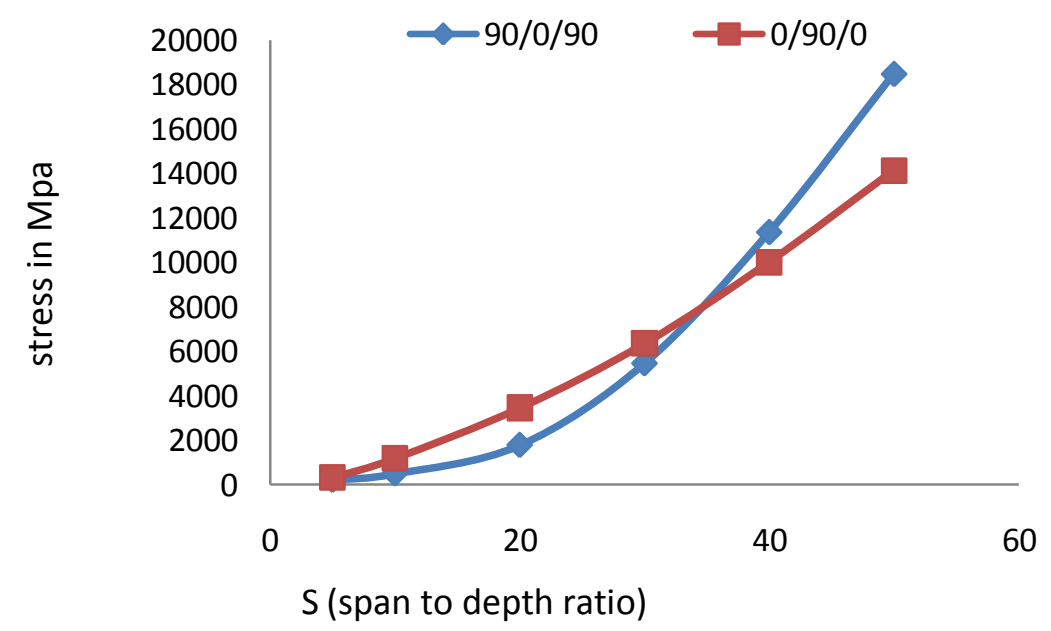

Figure 10 variation of stress with respect to $S$ for clamp-free laminate 


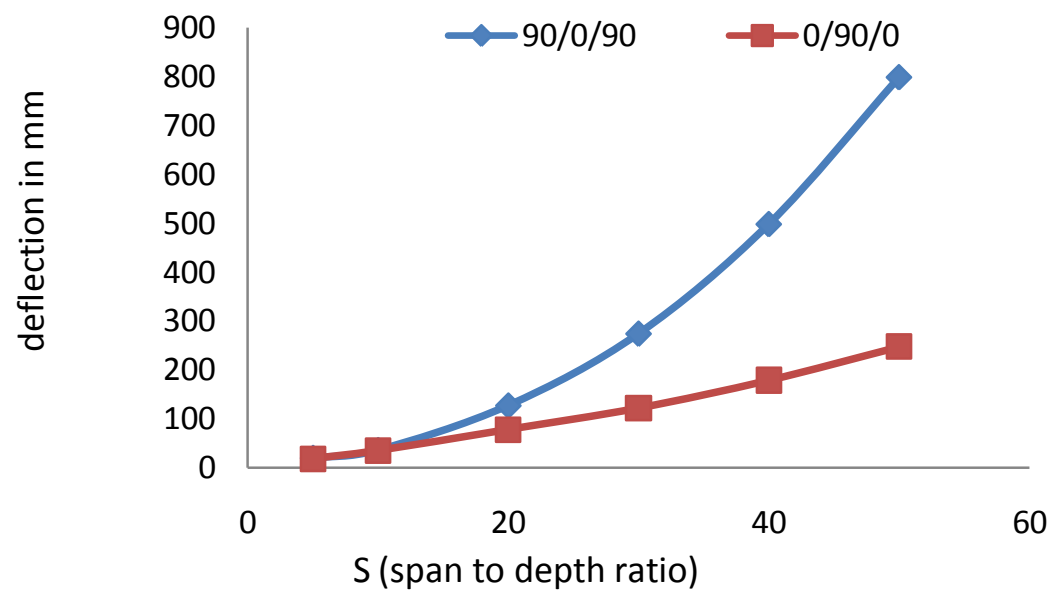

Figure 11 variation of deflection with respect to $S$ for clamp-free laminate

From Figs. 12 and 13 it is observed that in clamped condition also the graphs for deflection and stresses follows the same pattern as above two cases but the values in this case are little less than the hinged condition. Here also maximum deflection and stress values are obtained in a stacking sequence of 90/0/90 and minimum values are obtained in a stacking sequence of 0/90/0. It is observed that maximum stress is developed at supports in the stacking sequences that start with $0^{0}$. This is due to the axial compression developed and due to high stiffness of the bottom layer. In these cases also the maximum stresses developed at the center are considered in order to maintain similarity between all the cases by neglecting the end effects.

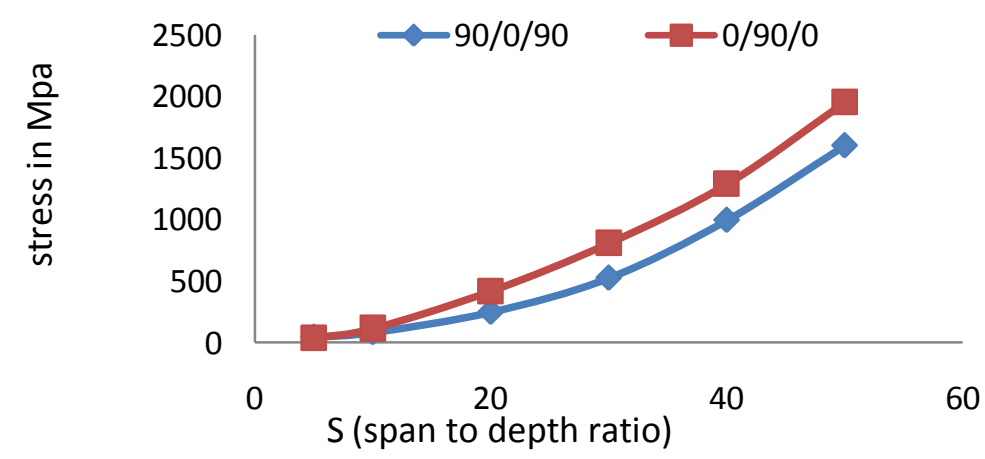

Figure 12 variation of stress with respect to $S$ for clamp-clamp laminate

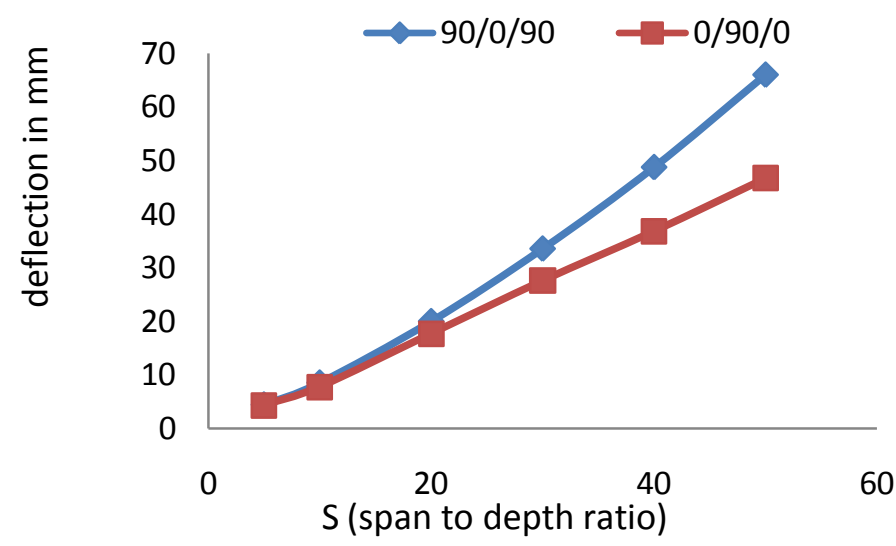

Figure 13 variation of deflection with respect to $S$ for clamp-clamp laminate

It is observed that the deflection and stresses developed in the glass laminate are very high when compared with the graphite epoxy laminate this is due to the material properties. 


\section{Conclusions}

A two-dimensional plane strain finite element model is developed for analysis of cross-ply laminates under cylindrical bending. The effect of boundary conditions, stacking sequence, material effect and span to depth ratio on the response of the structure is studied. It is observed that stresses and deflections are increasing in a non-linear form with increase in the $\mathrm{S}$ value. Of all the cases considered, it is found that stresses and deflections are more in a stacking sequence of 90/0/90 and least in the stacking sequence of 0/90/0. It is also found that stresses and deflections are less in laminate using graphite epoxy than the laminate using glass.

\section{References}

[1] Pagano N.J., "Exact solutions for composite Laminates in Cylindrical Bending" Journal of Composite Materials Vol.3 (1969), p. 398.

[2] Pagano N.J., "Exact solutions for Rectangular Bidirectional Composites and Sandwich Plates" Journal of Composite Materials Vol.4 (1970), p. 20.

[3] Pagano N.J., "Influence of shear coupling in Cylindrical Bending of Anisotropic Plates" Journal of Composite Materials Vol.4 (1970), p. 330

[4] Lekhnitskii S.G., "Theory of Elasticity of an Anisotropic Body", Holden Day (1963).

[5] Kerr, A.D., “An Extension of the Kantorovich Method”, 1968, Q. Appl. Math., 4, pp. 219-229.

[6] Santosh Kapuria and Poonam Kumari, "Extended Kantorovich Method for Three-Dimensional elasticity solution of Laminated Composite structures in Cylindrical Bending", Journal of Applied Mechanics, ASME, November 2011, Vol.78/ 061004-1 to 061004-8.

[7] Ji-fan He, "Cylindrical bending of arbitrary cross-ply laminated plates, Composite Structures (ISSN 0263-8223), vol. 21, no. 2, 1992, p. 67-74.

[8] J.G. Ren., "bending theory of laminated plate",Composite Science and technology vol. 27, Issue 3, 1986, Pages 225- 248.

[9] Ashraf M. Zenkour, "Three-dimensional Elasticity Solution for Uniformly Loaded Cross-ply Laminates and Sandwich Plates", Journal of Sandwich Structures and Materials May 2007 vol. 9 no. 3 213-238.

[10] Bala Krishna Murthy V., "Analysis of Stresses Around Cutouts in Skew Laminated Composite Plates", PhD Thesis, JNTU Hyderabad, 2005.

[11] ANSYS Reference Manuals, 2011.

[12] K J V S Praveen, "Analysis of crossply laminate under cylindrical bending using plane strain approach", international conference, INCRAME-2012... 